\title{
Psychopathology
}

Psychopathology 2007;40:8-13

DOI: $\underline{10.1159 / 000096384}$
Received: June 10, 2005

Accepted after revision: December 19, 2005

Published online: October 19, 2006

\section{Interpersonal Problem Areas and Onset of Panic Disorder}

\author{
P. Scocco ${ }^{\text {a }}$ I. Barbieri ${ }^{\text {b }}$ E. Frank ${ }^{\text {c }}$ \\ ${ }^{a}$ Department of Mental Health and ${ }^{b}$ Foniatric Medical Centre, Padua, Italy; ${ }^{c}$ Western Psychiatric Institute and \\ Clinic, University of Pittsburgh Medical Center, Pittsburgh, Pa., USA
}

\section{Key Words}

Interpersonal psychotherapy · Panic disorder · Life events

\begin{abstract}
Background: Numerous studies indicate that stressful life events are key precipitants of psychological disturbances. Severe stress often precedes the onset or exacerbation of illness in vulnerable individuals and may be of primary importance in the genesis of some mental disorders. Several authors have suggested that major life events play a role in the development of panic-related symptoms. The aim of this study was to examine the presence of stressful life events, in particular events focused in the interpersonal psychotherapy problem areas (grief, role disputes, role transitions, interpersonal deficits), in patients suffering from panic disorder. Methods: We interviewed 55 patients suffering from panic disorder, with or without agoraphobia, in accordance with the diagnostic criteria specified in MINI PLUS. The panic attack profile was evaluated with the Panic Attack and Anticipatory Anxiety Scale. We assessed the ability to adapt to and derive satisfaction from the social environment with the Social Adjustment Scale Self Report and interpersonal problems with Interpersonal Questionnaire. Results: Using the Interpersonal Questionnaire
\end{abstract}

we found that all subjects had had relevant interpersonal problems in the year preceding the onset of PD: $92.7 \%$ had experienced a role transition, $85.5 \%$ interpersonal deficits, $74.5 \%$ a role dispute and $38.2 \%$ had suffered the loss of a relative or significant other. These results were confirmed by Paykel's scale, on which the whole sample reported a high frequency of life events in the 6 months before onset of illness. These preliminary data suggest a rationale for the therapeutic strategies of interpersonal psychotherapy in individuals with panic disorder.

Copyright (C) 2007 S. Karger AG, Basel

\section{Introduction}

The presence of life events preceding the onset of panic disorder (PD) has been frequently described in the literature, although authors have used different time frames and evaluation instruments to address this question. Using the Social Readjustment Rating Scale [1], Pollard et al. [2], assessed 50 individuals with agoraphobia and found $62 \%$ reported life events involving loss, separation, or conflict, $12 \%$ had stated injury illness, $54 \%$ new responsibilities and $56 \%$ miscellaneous events.

Rapee et al. [3] asked 64 subjects suffering from PD with agoraphobia to complete a modified version of the Life Experience Survey, a 76-item self-report survey of

\section{KARGER \\ Fax +41613061234 E-Mail karger@karger.ch} www.karger.com
(C) 2007 S. Karger AG, Basel 0254-4962/07/0401-0008\$23.50/0

Accessible online at:

www.karger.com/psp
Dr. Paolo Scocco

Community Mental Health Centre

Via Buzzaccarini 1

IT-35124 Padova (Italy)

Tel. +39 049692 416, Fax +39 049880 7050, E-Mail scocco.paolo@virgilio.it 
positive and negative life experiences. Almost all (98.4\%) reported at least one major life event that had occurred in the 6-month period prior to the onset of their disorder; $60.9 \%$ of these events concerned health, $73.4 \%$ relationships, 78.1\% career/finance and 90.6\% miscellaneous. In an interview of 50 patients suffering from panic attacks and agoraphobia, Kleiner and Marshall [4] found that in the year preceding their first panic attack, the majority $(84 \%)$ experienced severe and prolonged marital or relationship conflicts. Other common stressors reported were family conflicts (64\%), divorce (26\%), marriage (22\%), social isolation (22\%), death of a loved one $(22 \%)$, and change of residence (18\%). All subjects reported precipitants involving more than one stressor, with at least one being of an interpersonal nature. RoyByrne et al. [5] examined life events during the year prior to the onset of panic attacks in 44 patients with $P D$ and 44 healthy control subjects. The patients with PD experienced significantly more (and typically more distressing) life events than control subjects. From most to least frequently reported were: change in recreation/social routine $(\mathrm{n}=16)$, move to a better home/neighborhood $(n=14)$, move to a comparable home/neighborhood $(n=11)$, move to another city $(n=11)$, and increased workload $(n=11)$.

Faravelli and Pallanti [6] found that patients experienced a significantly greater amount of life stress, as measured by Paykel's event list, during the 12 months prior to the onset of PD.

The impact of life events on PD onset has never been studied from an interpersonal point of view. The aim of this study was to examine the occurrence of interpersonal events representative of the four focal problem areas addressed in interpersonal psychotherapy (IPT) - grief, interpersonal disputes, role transitions and interpersonal deficits $[7,8]$ - in the year prior to the onset of PD.

\section{Method}

We contacted the Italian Association for Anxiety Disorders of Agoraphobia and Panic Disorder to ask members of its self-help groups to fill out our test packages. We used the forum of this association's web site to conduct our study so that potential participants had the possibility of evaluating the tests in advance. One of us (I.B.) contacted each patient to offer help and support in completing the instrument should it be required.

Of the 104 subjects contacted, 49 refused to collaborate, claiming they either had no time, or they considered the instruments too limited to adequately investigate their severe and unique symptoms. Fifty-five individuals were enrolled and interviewed, yielding a response rate of $52.9 \%$.

Interpersonal Problem Areas and Onset of Panic Disorder
All subjects had a primary diagnosis of PD, with or without agoraphobia, as established by the MINI PLUS [9], a short structured interview for the major disorders for both DSM-IV Axis I and ICD-10. Patients with comorbid major depressive disorder were included in the study, while those with substance abuse/dependence disorder were excluded.

The test packages administered included:

- The Panic Attack and Anticipatory Anxiety Scale [10] to determine the panic attack profile: 'situational attacks' or 'unexpected attacks,' full blown vs. limited symptom attacks. This scale rates from 0 to 10 , with 10 representing the maximum intensity.

- The Interview for Recent Life Events [11] to assess life events occurring 12 months prior to the onset of illness. The scale consists of 63 events divided into 10 categories: work, education, economy, health, loss, emigration, sentimental life, legal problems, family/society, and marital situation.

- The Social Adjustment Scale - Self Report (SAS-SR) [12] to focus attention on patients' social and community adjustment. It consists of 42 questions measuring either instrumental or expressive role performance over the past 2 weeks in 6 major areas of functioning: work as an employee, house wife or student, social and leisure activities, relationship with extended family, marital role, parental role, and membership in the family unit. This instrument employs a $1-5$ scale, with 5 representing the maximum maladjustment.

- The Interpersonal Questionnaire (IQ) [Frank and Andrade, pers. commun. 2003], which queries life events that are relevant to the four focal interpersonal problem areas addressed in IPT: unresolved grief, role transitions, interpersonal role disputes and interpersonal deficits. In this case, the time frame is the year preceding the onset of the subject's disorder.

\section{Results}

A diagnosis of $\mathrm{PD}$, with or without agoraphobia, was confirmed, and substance abuse/dependence was excluded in all 55 subjects ( 37 women, 18 men; mean age 39.29 years, SD 12.51). Of the 55 subjects, 19 (34\%) presented with comorbid major depression; mean age at disorder onset was 26.71 (SD 10.26) years.

The majority of patients lived in northern Italy (northwest $58.2 \%$; north-east $30 \%$ ), and $58.2 \%$ had completed secondary school. In terms of occupational status, the majority of subjects were employed outside the home (67.3\%), followed by housewives (10.9\%) and students $(9.1 \%)$. More than half of the subjects were single (54.5\%) and $7.3 \%$ were divorced; $45.5 \%$ lived with their family of origin and $41.8 \%$ with acquired family.

When asked how they managed their PD, the majority of subjects $(62.27 \%)$ reported using only medication, while $20 \%$ reported being treated with both medication and psychotherapy ( $11 \%$ cognitive behavior therapy and $9 \%$ psychodynamic therapy). 
Table 1. The Interpersonal Questionnaire (excerpt)

\begin{tabular}{|c|c|c|c|}
\hline & & $\mathrm{n}$ & $\%$ \\
\hline A4 & Are you able to talk openly with him/her (the closest person to you) about yourself? & 37 & 67.27 \\
\hline A5 & Is there someone else you can confide in about yourself? & 36 & 65.45 \\
\hline A6 & Are you able to ask any of the important people in your life for help when you have problems? & 45 & 81.82 \\
\hline A7 & Have you had difficulty getting along with any of the important people in your life over the past year? & 26 & 47.27 \\
\hline A8 & Do you think your relationship with any of these people has been affected by your panic disorder? & 37 & 67.27 \\
\hline A10 & Do you think that your relationship with any of these people has had an impact on you and your panic disorder? & 32 & 58.18 \\
\hline $\mathrm{C} 1 \mathrm{~A}$ & $\ldots$ did anyone close to you die? & 16 & 29.09 \\
\hline $\mathrm{C} 1 \mathrm{~B}$ & Is there anyone whose death you think you have never really gotten over? & 19 & 34.55 \\
\hline $\mathrm{C} 2$ & ...did you lose contact with someone or see much less of someone important to you? & 28 & 50.91 \\
\hline $\mathrm{C} 4 \mathrm{a}$ & ...starting, graduating, or quitting school? & 14 & 25.45 \\
\hline $\mathrm{C} 4 \mathrm{~b}$ & ...starting a new job? & 17 & 30.91 \\
\hline $\mathrm{C} 4 \mathrm{c}$ & experiencing a change in your job, such as receiving a promotion, a demotion, or being fired? & 11 & 20 \\
\hline $\mathrm{C} 4 \mathrm{~d}$ & ...quitting or retiring from a job? & 3 & 5.45 \\
\hline $\mathrm{C} 4 \mathrm{e}$ & ...getting married or remarried? & 3 & 5.45 \\
\hline $\mathrm{C} 4 \mathrm{f}$ & ...getting divorced or separated? & 2 & 3.64 \\
\hline $\mathrm{C} 4 \mathrm{~g}$ & ...having, adopting, or fostering a child? & 4 & 7.28 \\
\hline $\mathrm{C} 4 \mathrm{~h}$ & ...having the last of your children leave home? & 4 & 7.28 \\
\hline $\mathrm{C} 4 \mathrm{i}$ & ...having a child return home to live? & 0 & - \\
\hline $\mathrm{C} 4 \mathrm{j}$ & ...having a child report for military duty? & 0 & - \\
\hline $\mathrm{C} 4 \mathrm{k}$ & ...moving? & 7 & 12.73 \\
\hline C5 & Have you had financial problems? & 12 & 21.82 \\
\hline C6 & Have you had any medical problems other than your panic disorder? & 13 & 23.64 \\
\hline $\mathrm{C} 7$ & Was there a serious illness in your family? & 18 & 32.73 \\
\hline $\mathrm{C} 8$ & Have you had serious problems (arguments, cut-offs, etc.) in any of your relationships, such as & & \\
\hline $\mathrm{C} 8 \mathrm{a}$ & ...with your partner or spouse? & 14 & 25.45 \\
\hline $\mathrm{C} 8 \mathrm{~b}$ & ...with your in-laws? & 7 & 12.73 \\
\hline $\mathrm{C} 8 \mathrm{c}$ & ...with your children? & 1 & 1.82 \\
\hline $\mathrm{C} 8 \mathrm{~d}$ & ...with your parents? & 14 & 25.45 \\
\hline $\mathrm{C} 8 \mathrm{e}$ & ...with your boss or colleagues at work? & 5 & 9.09 \\
\hline $\mathrm{C} 8 \mathrm{f}$ & ...with your friends? & 5 & 9.09 \\
\hline $\mathrm{C} 8 \mathrm{~g}$ & ...with your neighbors? & 1 & 1.82 \\
\hline $\mathrm{C} 8 \mathrm{~h}$ & ...with anyone else important to you? & 14 & 25.45 \\
\hline
\end{tabular}

The most frequently reported kinds of attacks according to the Panic Attack and Anticipatory Anxiety Scale were intense situational (65\% of subjects), partial situational (38.2\%) and intense unexpected attacks (38.2\%). Almost one quarter (23.6\%) reported partial unexpected attacks, with a mean intensity rating of 6.58 . The test also evaluated the percentage of time during the week before test completion that subjects spent fearing either a panic attack or being in a situation that could provoke a similar event. In our sample, the mean percentage of time was $51.84 \%$.

We found relevant interpersonal problem events were present in all subjects during the 12 months preceding the onset of PD. All subjects reported events in at least 2 interpersonal problem areas: $92.7 \%(\mathrm{n}=51)$ experienced a role transition (e.g. starting a new job or school, relative's serious illness, economic problems), $85.5 \%(n=47)$ interpersonal deficits (e.g. inadequate or no relationships), $74.5 \%(n=41)$ reported an interpersonal dispute with a partner or parents, and $38.2 \%(n=21)$ reported a death of a relative or significant other (table 1).

Using the Paykel instrument, we found the majority of subjects reported events concerning family/society (54.55\%), work (49.09\%), health (47.27\%), sentimental life (38.18\%), education (29.09\%) and loss (29.09\%) areas, while only a minority reported events concerning finances $(25.45 \%)$, emigration (18.18\%), marriage $(10.9 \%)$ and legal problems $(3.64 \%)$. We further classified these events as 'entrances' and 'exits' (events involving someone's entrance or exit from the subject's life); 'desirable events' and 'undesirable events', and 'controlled events' and 'non-controlled events': 94.6\% 
had at least one undesirable event, 78.19\% had a noncontrolled event, and $61.82 \%$ experienced an exit. The more frequent events reported were: serious illness of a family member $(34.5 \%)$, change of work $(32.7 \%)$, change in work condition (23.6\%), separation from a significant other $(21.8 \%)$, breaking an engagement $(18.2 \%)$, arguments with boss or co-worker $(16.4 \%)$, death of close family member (16.4\%), change in work hours (14.5\%), finishing school or schooling interruption $(14.5 \%)$, financial difficulties $(14.5 \%)$ and increased arguments with resident family member $(14.5 \%)$.

We found the presence of agoraphobia or comorbid depression had no effect on the probability of endorsing any interpersonal event evaluated by either the IQ or Paykel's instrument, or on the frequency of entrances/exits, desirable/undesirable and controlled/non-controlled events appraised by Paykel's instrument, or the four focal problem areas of the IQ.

The areas in which subjects reported greater dysfunction on the SAS-SR were social and leisure activities (mean 2.49, SD 0.73), marital role (mean $=2.35$, SD 0.65) and relationships with extended family (mean 2.27; SD $0.74)$. The areas where subjects reported somewhat better adjustment involved parental role (mean $=1.95, \mathrm{SD}$ 0.67 ), membership in the family unit (mean $=2.08$, SD 0.97 ) and work (mean $=2.17$, SD 1.25). The SAS evaluation yielded an overall mean score of 2.03 .

\section{Discussion}

In this study we considered a selected and probably non-representative sample of patients with PD. Although the extent of comorbidity with major depression (34\%) is similar to that found in other studies (e.g. $31 \%$ in the study of Apfeldorf et al. [13]), we cannot know to what extent the opportunity to preview the questionnaires may have biased the sample in favor of those with more life events.

All subjects were undergoing treatment, in some cases combined (drugs, psychotherapy, self-help group). Despite being in treatment, all of the subjects were seriously ill, with active, symptomatic PD, along with some problems in social and community adjustment.

The performance of our sample on the SAS-SR was poorer than that observed by Weissman et al. [14] in their community sample (mean of 2.03 vs. 1.59 ) and among subjects with schizophrenia (mean of 2.03 vs. 1.96), although it was better than that of the acutely depressed (mean of 2.03 vs. 2.53 ) and alcoholic subjects (mean of 2.03 vs. 2.23 ) they studied.

Our sample could be a selected sample with a more frequent occurrence of interpersonal problems that agreed to participate in our study to improve their comprehension of their interpersonal life. This could also explain their participation in the self-help group.

The high life event frequency reported on the IQ was consistent with subjects' reports on the Paykel instrument. We found that almost all subjects reported one or more interpersonal event in the year prior to the onset of PD. The most frequent interpersonal problem area reported was 'role transition' and the least frequent was 'grief'. Surprisingly, over $80 \%$ reported interpersonal deficits, with relationships being either inadequate or not present at all. Usually, this area is rarely addressed in IPT with depressed patients. Markowitz et al. [15] found that it had the lowest interrater reliability, perhaps because it is the least well defined and, in contrast to the other problems areas of IPT, is characterized by the absence of something, not by its presence [16]. However, panic and especially panic-agoraphobia may lead to interpersonal deficits through social isolation much more than depression does.

We found the presence of agoraphobia or comorbid depression had no effect on the frequency of interpersonal events in the year prior of PD onset. Apfeldorf et al. [13] used the Inventory of Interpersonal Problems to assess impairment in relationships with others in a sample of patients with PD with or without anxiety and depression comorbidity. These authors reported a higher Inventory of Interpersonal Problems mean score for the PD with comorbid affective disorders group than for the PD-only group.

The difference between our results and those of Apfeldorf et al. [13] might be attributable to the difference in assessment method: in our case, the IQ only takes account of the 12 months before illness onset, whereas Apfeldorf et al.'s IIP weighted all events according to the time elapsing between the event and the disorder onset. In fact, the relational network of patients with comorbodities could have damaged their relational network during the longer duration of illness, more than the patients with only PD.

Milrod et al. [17] also examined the frequency of interpersonal loss events, but within a smaller time frame (6 weeks) from the onset of PD and reported 47\% of patients had experienced a significant interpersonal loss.

Our observations agree with the results of Faravelli et al. [6]. These authors also used Paykel's event list to as- 
sess life events during the 12 months prior to the onset of PD in 64 patients compared with a control group of 78 healthy subjects. The patients with PD experienced a significantly greater amount of life stress regardless of how it was measured. Forty-one patients $(64 \%)$ had had at least one severe event, compared with 27 control subjects (34.6\%). A subject was considered to have experienced a severe event when any of the top 20 events on Paykel's list, consisting of 61 events ranked in descending order of severity, had occurred. Of the patients and control subjects, $40(62.5 \%)$ and $22(28.2 \%)$, respectively, had suffered at least one loss; $48(75 \%)$ and $36(46.1 \%)$ had experienced at least one threat event, and $48(75 \%)$ and 42 $(53.8 \%)$ had had at least one adjustment event. Loss events had the strongest correlation with PD.

Nevertheless, Seivewright et al. [18] did not find an association between loss life events and depression score on the Montgomery-Åsberg Depression Rating scale) or between addition events and anxiety score (Brief Scale for Anxiety). Conflict events consistently led to higher scores for both depression and anxiety rating.

Through IPT, one could provide the same kind of management of life events related to anxiety symptoms as is provided in relation to depressive symptoms, following the same rationale. We have emphasized that despite being in treatment, all of the subjects of our sample were seriously ill, with active, symptomatic PD. This could be explained by the fact that the life events they reported can be clearly related to deteriorating conditions and that greater numbers of life events can be followed by an increase in symptoms. Besides, more life events could be associated with dramatic and dependent personality disorders, reinforcing other evidence that many of these disorders are internally generated by personality characteristics and cannot be regarded as truly independent [18].
This study has two methodological limitations, the lack of a control sample and the number of years elapsing from PD onset. The latter could cause a measurement error due to inability to recall life events preceding PD onset. However, some authors have documented the absence of the distorting effect of time of recall on reporting life events over a range of 1-16 years, in particular when patients have experienced a small number of significant life events $[19,20]$.

\section{Conclusion}

Our results indicate that in the year prior to the onset of PD, most of the subjects we studied experienced problems consistent with the four IPT problem areas and were experiencing difficulties in many of the interpersonal areas that could be addressed by IPT. While this suggests a rationale for the therapeutic strategies of IPT in individuals with PD, further research is required to evaluate the suitability of this therapeutic option with PD patients, particularly those who have suffered from PD for many years. Nevertheless, one of us (E.F.) has reported positive results for a modification of IPT for depression comorbid with lifetime panic symptomatology [21]. It remains to be seen, first, whether this adaptation will prove superior to standard IPT in the treatment of such individuals and, second, whether traditional IPT or this modification are effective in the treatment of primary PD.

\section{Acknowledgments}

We would like to thank Dr. Giovanni Colombo for his suggestions and collaboration.

\section{References}

1 Holmes TH, Rahe RH: The Social Readjustment Rating Scale. J Psychosom Res 1967;11: 213-218.

-2 Pollard AC, Pollard HJ, Corn KJ: Panic onset and major events in the lives of agoraphobics: a test of contiguity. J Abnorm Psychol 1989;3: 318-321.

-3 Rapee RM, Litwin EM, Barlow DH: Impact of life events on subjects with panic disorder and on comparison subjects. Am J Psychiatry 1990; 147:640-644.
Kleiner L, Marshall WL: The role of interpersonal problems in the development of agoraphobia with panic attacks. J Anxiety Disord 1987;1:313-323.

$>5$ Roy-Byrne PP, Geraci M, Uhde TW: Life events and the onset of panic disorder. Am J Psychiatry 1986;143:1424-1427.

6 Faravelli C, Pallanti S: Recent live events and panic disorder. Am J Psychiatry 1989;146: $622-626$.

7 Klerman GL, Weissman MM, Rounsaville BJ, Chevron ES: Interpersonal Psychotherapy of Depression. New York, Basic Books, 1984.
8 Weissman MM, Markowitz JC, Klerman GL: Comprehensive Guide to Interpersonal Psychotherapy. New York, Basic Books, 2000.

9 Sheehan DV, Lecrubier Y, Harnet Sheehan K, Amorim P, Janavs J, Weiller E, Hergueta T, Baker R, Dunbar G: The Mini International Neuropsychiatric Interview (M.I.N.I.): The development and validation of a structured diagnostic psychiatric interview. J Clin Psychiatry 1998; 13:26-34.

10 Sheehan DV: Sheehan Anxiety and Panic Attack Scales. Kalamazoo, Upjohn, 1983. 
11 Paykel ES, Prusoff BA, Uhlenhuth EH: Scaling of life events. Arch Gen Psychiatry 1971;25: 340-347.

12 Weissman MM, Bothwell S: Assessment of social adjustment by patient self report. Arch Gen Psychiatry 1976;33:1111-1115.

13 Apfeldorf WJ, Spielman LA, Cloitre M, Heckelman L, Shear MK: Morbidity of comorbid psychiatric diagnoses in the clinical presentation of panic disorder. Depress Anxiety 2000; 12:78-84.

14 Weissman M, Prusoff BA, Thompson WD, Harding PS, Myers JK: Social adjustment by self-report in a community sample and in psychiatric outpatients. J Nerv Ment Dis 1978; 166:317-326.
15 Markowitz JC, Leon AC, Miller NL, Cherry S, Clougherty KF, Villalobos L: Rater agreement on interpersonal psychotherapy problem areas. J Psychother Pract Res 2000;9:131-135.

16 Andrade AC, Frank E, Swartz HA: A proposed system for re-classification of interpersonal deficits. Bull ISIPT 2004;3:2.

17 Milrod B, Leon AC, Shear MK: Can interpersonal loss precipitate panic disorder? Am J Psychiatry 2004;161:758-759.
18 Seivewright N, Tyrer P, Ferguson B, Murphy $\mathrm{S}$, Johnson T: Longitudinal study of the influence of life events and personality status on diagnostic change in tree neurotic disorders. Depress Anxiety 2000;11:105-113.

19 Roy-Byrne PP, Geraci M, Uhde TW: Live events obtained via interview: the effect of time recall on data obtained in controls and patients with panic disorder. J Affect Disord 1987; 12:57-62.

20 Brown EW, Harris T: Fall-off in the reporting of life events. Soc Psychiatry 1982;17:23-28.

-21 Cyranowski JM, Frank E, Shear MK, Swartz H, Fagiolini A, Scott J, Kupfer DJ: Interpersonal psychotherapy for depression with panicspectrum symptoms (IPT-PS): a pilot study. Depress Anxiety 2005;21:140-142. 